\title{
CULTURA JUVENIL Y CULTURA ESCOLAR EN LA ENSEÑANZA MEDIA DEL URUGUAY DE HOY: UN VINCULO A CONSTRUIR*
}

\author{
ERNESTO RODRÍGUEZ ${ }^{* *}$
}

\section{INTRODUCCIÓN}

COMO SE HA SEÑALADO en muy diversos estudios y evaluaciones realizadas en los últimos años, la enseñanza media se ha transformado radicalmente en las últimas décadas en casi toda América Latina, y nuestro país no ha sido una excepción al respecto. Entre muchos otros cambios relevantes, hay coincidencia en destacar la ampliación sustancial de la matrícula (masificación en la mayor parte de los casos) y la creciente heterogeneización de la «clientela» correspondiente, aludiendo al ingreso de estudiantes provenientes de estratos medios y

* Documento de Trabajo elaborado inicialmente para su presentación ante la Unidad Ejecutora de los Programas de Educación Media y Formación Docente (MESyFOD-UTU/BID) en el marco de los Acuerdos de Trabajo actualmente existentes (con vistas a la ampliación de la cooperación en el denominado «Espacio Adolescente») y revisado a posteriori para su presentación adicional ante el Consejo de Educación Secundaria (CES) a los efectos de elaborar posibles acciones en común en el Liceo $\mathrm{N}^{\circ} 12$, en respuesta a los recientes sucesos de pública notoriedad.

** Sociólogo uruguayo. Experto en Desarrollo Social, Consultor de Organismos Internacionales y Asesor de Gobiernos y ONGS en Diseño y Evaluación de Programas Sociales. Ex Director del Instituto Nacional de la Juventud del Uruguay (INJU) y Ex Presidente de la Organización Iberoamericana de la Juventud (OIJ). E-mail: erodrigu@adinet.com.uy. 
bajos que hasta hace no mucho tiempo, no llegaban a este nivel de enseñanza.

Esto ha traído toda clase de complicaciones en la dinámica interna de los establecimientos educativos medios, que no estaban preparados para asumir estos cambios tan vertiginosos como profundos, destacándose en particular, las limitadas capacidades de «retención» de quienes ingresan, que en una gran proporción desertan tempranamente o arrastran atrasos considerables en el desarrollo de su pasaje por la enseñanza media. Los estudios presentados en el seminario sobre «Expectativas de los jóvenes y sus familias respecto a la educación», organizado por la Unidad Ejecutora de los Programas MESyFOD y UTU/BID el pasado 31 de mayo del 2001, son más que elocuentes respecto al caso uruguayo.

La presentación que en particular realizara Santiago Cardozo en dicho seminario, permite y estimula a la reflexión sobre un tema particularmente relevante (en especial para quienes trabajamos con jóvenes desde hace muchos años), esto es, la relación existente entre cultura juvenil y cultura escolar, al menos, en sus rasgos predominantes (más allá de las especificidades que ambas siempre tienen en cada caso particular). En lo que me es personal, he estado analizando estos temas en diversos contextos nacionales, especialmente en Argentina, Chile, Colombia y México, y en todos los casos existen iniciativas y enfoques estratégicos que podrían ser extremadamente útiles para el desarrollo de acciones más pertinentes y oportunas en el futuro en nuestro país. En particular, el Espacio de los Jóvenes desarrollado en Chile entre 1995 y 2000 y el Programa de Escuelas para Jóvenes que se comienza a implementar en Argentina, deberían ser referentes claros al respecto.

Por ello, en las páginas que siguen se realiza una esquemática presentación de los puntos neurálgicos del tema, se analizan las experiencias latinoamericanas anteriormente mencionadas, y se revisan los antecedentes del caso uruguayo (incluyendo algunos comentarios sobre el «espacio adolescente» y sobre el programa desarrollado por la Asociación Cristiana de Jóvenes (ACJ) en el Liceo $\mathrm{N}^{\circ} 46$ de Paso de la Arena durante el año pasado), para tratar de extraer algunas conclusiones útiles para pensar el diseño de enfoques más pertinentes en estas materias, que podrían ser eventualmente implementados en los próximos años. Para facilitar la exposición de las ideas que se quiere trasmitir, se ha optado por evitar la inclusión de las citas específicas (en cada caso concreto) de los muchos trabajos consultados, que en 
cualquier caso se incluyen al final de estas notas, para dejar la constancia correspondiente.

Por último, importa comentar que aunque estas notas no se inspiran en ningún acontecimiento en particular, se tornan más contingentes a la luz de los hechos acaecidos hace algunas semanas en el Liceo $\mathrm{N}^{\circ} 12$ del Parque Batlle, y pueden contribuir a explicar lo ocurrido e intentar un posible camino en busca de soluciones de fondo al respecto. ${ }^{* * *}$

\section{EL PUNTO DE PARTIDA: \\ LA SITUACIÓN ACTUALMENTE EXISTENTE}

Comencemos por el principio, evaluando esquemáticamente la situación en la que estamos.

\section{a) Las culturas juveniles como objeto de análisis para las ciencias sociales}

Las ciencias sociales en general, a partir del trabajo pionero de algunos sociólogos, que luego retomaron varios antropólogos, psicólogos y comunicadores sociales (entre otros), están dedicando una creciente atención al tema de las culturas juveniles. No tiene sentido hacer - en el marco de estas notas - un análisis exhaustivo de los avances concretados, pero importa destacar algunas de las orientaciones principales al respecto, seleccionando aquellas que pueden ser más útiles para nuestros propósitos particulares.

Así, la mayor parte de los estudios conocidos, han tratado de centrarse en el análisis de la influencia de los grupos de pares en la socialización juvenil, como uno de los principales agentes de generación y transmisión de «culturas» específicas al respecto. Pero mientras en algunos casos esto se ha concretado a través del análisis de ciertas «prácticas» concretas (la apropiación de los centros comerciales, la cultura de la noche, etc.), otros se han concentrado en analizar las denominadas «tribus urbanas» (grupos de esquina, barras bravas en el

*** Se refiere a la reacción violenta de los estudiantes, el 24 de agosto del 2001, quienes apedrearon el liceo ocasionando diversos daños a la propiedad del establecimiento, que en opinión de los jóvenes, fue en protesta a la suspensión de la limpieza del local por tres semanas, debido a la falta de recursos para esas labores. Esta situación generó un amplio debate y polémica en la opinión pública uruguaya (N. del E.). 
fútbol, etc.) y un tercer grupo se ha concentrado en el análisis de diversas expresiones culturales juveniles, particularmente ligadas a la música (especialmente el rock).

En todo caso, más allá de las notorias diferencias constatadas en el análisis de grupos juveniles diversos (urbanos y rurales, de estratos medios y bajos, varones y mujeres, etc.) lo que se verifica en todos los casos es la significativa importancia del grupo de pares en esta etapa de la vida, lo que contrasta claramente con el mayor protagonismo de los padres y de los maestros (docentes) en tanto referentes centrales de la socialización de los niños. Sin duda, esto ha sido destacado casi desde siempre por la psicología, pero estos estudios han acumulado sólidas evidencias en contextos muy diversos, reafirmando esta constatación.

¿Cuál ha sido la utilización práctica de estos «hallazgos» provenientes de los estudios especializados? Al parecer, mientras la familia y la educación institucionalizada no parecen haber incorporado estos aprendizajes en el desarrollo de sus vínculos con los jóvenes, lo contrario parece estar ocurriendo con las empresas privadas y los medios de comunicación, que constantemente (y de un modo creciente) recurren a este tipo de estudios para generar nuevas propuestas dirigidas a las generaciones jóvenes (de modos cada vez más segmentados, por cierto) y desarrollar así una creciente y más eficaz influencia en el consumo y la socialización juvenil, con la mediación de los grupos de pares al respecto.

Por su parte, desde la familia y desde la educación institucionalizada, la reacción a estos fenómenos parece seguir siendo más «defensiva» que "propositiva», generándose rechazos casi permanentes y sistemáticos a casi todo lo «juvenil». Desde el uso del cuerpo como emisor de «mensajes» (tatuajes, aros, etc.) o como instrumento de relación (juegos vistos como «violentos» desde el mundo adulto, por ejemplo) hasta la «irreverencia» con que los jóvenes se relacionan con los adultos (en el lenguaje, en la desaprobación sistemática de sus opiniones, etc.) casi todo lo «juvenil» es «censurado» y «castigado».

\section{b) Los liceos vistos por los jóvenes: un repertorio de problemas a analizar}

La presentación realizada por Santiago Cardozo en el Seminario de MESyFOD-UTU/BID anteriormente mencionado ofrece, como dijimos, elementos sumamente interesantes para reflexionar sobre 
estos temas, y en particular, ofrece un repertorio básico de problemas, en lo que atañe a la visión que los estudiantes tienen de sus liceos y de la educación que están recibiendo. A partir de los temas que Cardozo destaca, y agregando algunos otros por el estilo, se podría confeccionar la siguiente lista de temas a analizar:

i) Genéricamente, se constata una gran disconformidad de parte de los estudiantes con la educación que están recibiendo, lo que se transforma en un gran malestar que los agobia en sus intentos por recorrer con éxito su pasaje por la enseñanza media.

ii) Simplificando quizás exageradamente el problema, los estudiantes no le ven relevancia ni pertinencia a la educación que reciben, al menos en lo que atañe a la preparación para el cumplimiento de roles adultos (como ciudadanos y trabajadores, por ejemplo).

iii) Desde este punto de vista, para una gran parte de los estudiantes, la inversión de esfuerzos que realizan (tanto sus padres como ellos mismos) sobre todo en términos de tiempo vital asignado, no reditúa en una dimensión más o menos significativa.

iv) Estas percepciones, a su vez, generan un profundo pesimismo respecto a los resultados que pueden esperarse (aun teniendo en cuenta los esfuerzos realizados), una vez que se culmine el ciclo educativo como tal (total o parcialmente).

v) Consecuentemente, este conjunto de percepciones generan una muy débil integración de los estudiantes a la dinámica educativa como tal, lo que se expresa en una actitud de casi permanente «expectativa», a los efectos de decidir si se "persiste» o se «desiste».

vi) Todo este conjunto de fenómenos, se ve agravado con el paso del tiempo, en la medida en que se acumulan «fracasos», que son vividos claramente como limitaciones o carencias personales, y casi nunca como problemas del propio sistema educativo.

vii) En suma, el conjunto de los problemas destacados, generan una muy baja autoestima de parte de los estudiantes (y de sus padres), todo lo cual alimenta la propensión al abandono escolar, y fomenta su integración en circuitos marginales y excluyentes.

El resultado de todos estos procesos, es la profundización de la brecha existente entre matrícula escolar a nivel medio y años de educación acumulados, explicable por los niveles crecientes de abandono escolar o (la otra cara de la moneda) la disminución de la escasa capacidad de retención del sistema educativo como tal. Al respecto, 
importa tener en cuenta que durante los años noventa, según reporta la CEPAL en el Panorama social de América Latina 2000, el promedio de años de estudio en el Uruguay pasó de 8.3 a 8.4 años acumulados, ubicando al Uruguay entre los puestos más bajos de la escala regional en la actualidad (después de haber figurado entre los primeros en las décadas anteriores).

\section{c) El convidado de piedra: la competencia de los medios de comunicación}

El asunto se complica todavía más, si incorporamos al análisis la presencia creciente y mayoritariamente distorsionante de los medios masivos de comunicación en las dinámicas juveniles, tanto en lo que hace a su relación con la familia, como en lo que hace a su participación en grupos de pares y en el sistema educativo. El tema, que también ha sido ampliamente analizado desde las ciencias sociales, es sumamente relevante como para despacharlo en unos pocos párrafos, pero destaquemos lo más importante al respecto.

Para empezar, importa recordar que estas dinámicas han estado cargadas - casi desde siempre - por acusaciones y reproches mutuos terminantes, que han impedido «tender puentes» sobre las «aguas turbulentas» de la realidad. Así, algunos de dichos reproches destacan que el sistema educativo está estancado y no cuenta con los medios para modernizarse y ubicarse en las dinámicas del «tiempo real», mientras que otros se encargan de insistir en que los medios masivos de comunicación sólo venden excitación y no son capaces de trasmitir conocimientos útiles ni valores compartibles desde una perspectiva humanista, al tiempo que se señala — también-que éstos se «meten» excesivamente en la familia, distorsionando la convivencia entre sus miembros, etc.

Pero lo cierto es que, guste o no guste, los medios masivos de comunicación han logrado una mayor y más fluida sintonía con las nuevas generaciones, incorporando lenguajes propios de la gente joven y legitimando prácticas netamente juveniles (como el rock, por ejemplo), actuando con gran demagogia en lo que hace a la apropiación de las «irreverencias» y hasta las «prácticas transgresoras» de los jóvenes, que de ese modo se ven reflejados «tal como son» en la radio y en la televisión, fundamentalmente, que a estos efectos son los medios masivos de comunicación más relevantes. Personajes como Tinelli y Petinati son, en este sentido, verdaderos paradigmas al respecto. 
Las «reacciones», desde las familias y desde los establecimientos educativos, han sido netamente «defensivas», restringiéndose a la descalificación de los programas y personajes que se han transformado en verdaderos «ídolos» de las nuevas generaciones, y cuyos mensajes son atentamente escuchados, aun cuando se tratan temas «aburridos» (desde las percepciones juveniles) como la política o la economía. Un gran desconocimiento y hasta una escasa comprensión efectiva de estas dinámicas, alimentan la reacción de padres y docentes en estas materias, en el marco de una batalla que está perdida antes de comenzar, en la medida en que la «credibilidad» de los actores, está muy desigualmente repartida.

Incluso cuando la educación se decide a utilizar las nuevas tecnologías de la información y la comunicación, lo hace desde los paradigmas vigentes en la propia cultura escolar, con lo que produce programas excesivamente «formalizados» y totalmente «aburridos» para sus destinatarios, que reaccionan categóricamente imponiendo el «veto» correspondiente, es decir, la decisión de no atender en absoluto sus mensajes y propuestas. Una larga lista de evidencias empíricas respaldan estas afirmaciones en muy diversos contextos nacionales, y no hace falta extenderse en su «demostración». Sin embargo, nada impide que se pueda actuar de otro modo, como veremos más adelante, utilizando los medios masivos de comunicación para la práctica educativa, contemplando más y mejor las culturas juveniles.

\section{d) Las potencialidades de la socialización entre pares para el proceso educativo}

El tema es sumamente preocupante, sin duda, pero si lo miramos desde otro ángulo, la socialización entre pares podría jugar a favor del éxito de los estudiantes en el proceso educativo en particular y en su propio proceso de maduración personal y social como tal, con lo que la sociedad toda se vería ampliamente beneficiada. Varios son los argumentos al respecto, pero importa destacar aquí —al menosalgunos de los más relevantes.

En primer lugar, el grupo es visto por los jóvenes como lo único «seguro» y «verdadero», frente a un panorama donde predominan los datos «hostiles»: los padres «no los entienden», los profesores «son autoritarios» $\mathrm{y}$ «no saben nada», las normas del mundo adulto son muy «rígidas» $\mathrm{y}$ «sin fundamentos», los vecinos son «insoportables» («no dejan vivir» a los jóvenes, «todo les molesta», etc.) y hasta 
el sexo opuesto es un «problema» (sobre todo en la primera adolescencia, donde los grupos son «unisex»). Cualquier afirmación (por muy tribial o relevante que ésta sea) debe ser refrendada por el grupo, para que sea aceptada.

En segundo lugar, los propios estudios de los Programas MESyFOD y UTU/BID muestran que la propensión al abandono escolar es mayor en el caso de aquellos que tienen la mayor parte de sus amistades fuera del establecimiento educativo y se relacionan con jóvenes que ya han tenido experiencias fracasadas en estas materias. Dicho en términos positivos, la capacidad de los establecimientos educativos — en lo que hace a retención escolar - es más elevada entre aquellos jóvenes que cuentan con amistades predominantes dentro del propio establecimiento y se relacionan con jóvenes que han tenido éxito en materia educativa.

En tercer lugar, la experiencia de los liceos privados donde se consiguen mejores rendimientos educativos, indica que uno de los factores que «hacen la diferencia» es, precisamente, la existencia de grupos de pares - formales o informales - dentro de los propios establecimientos, que le ofrecen a los jóvenes un espacio de socialización más informal, que permite encarar una amplia gama de actividades curriculares y extracurriculares, con otra perspectiva y con más entusiasmo y compromiso efectivo de los jóvenes. Sin duda, no es el único factor explicativo, pero tiene una incidencia evidente.

Todo esto puede visualizarse claramente, por ejemplo, en la dinámica de la formación en valores. La experiencia indica que la misma es vista desde los jóvenes como excesivamente «ritualizada» y hasta «escindida» de la vida real de los referentes fundamentales del proceso (dirigentes políticos, empresarios, docentes, etc.) al tiempo que los jóvenes demandan una formación en valores más «auténtica» y «vivida» por quienes la profesan (los adultos referentes). Los jóvenes rechazan lo que consideran una evidente falta de consistencia entre lo que se dice y lo que se hace, práctica en la que caen - en su óptica- casi todos los adultos.

El tema, de por sí sumamente relevante, lo es más si se tiene en cuenta que los resultados que se consigan en estos dominios incidirán con mucha fuerza - directa o indirectamente- en las actitudes de los jóvenes en la sociedad, tanto en su calidad de ciudadanos como en su calidad de trabajadores, vecinos o consumidores.

Por lo dicho, en esta esfera se torna imprescindible relativizar la excesiva carga normativa con la que se trabaja, y al mismo tiempo, 
utilizar más y mejor la socialización entre pares como herramienta de trabajo.

\section{ALGUNAS RESPUESTAS INNOVADORAS A TENER EN CUENTA}

¿Qué se ha estado haciendo para enfrentar estos problemas, dentro y fuera de fronteras?

\section{a) Aprendiendo de otras experiencias (I): ¿Qué se ha estado haciendo en Chile?}

En el marco de la reforma educativa en marcha desde comienzos de los años noventa, en 1994 surgió en Chile el Programa de Mejoramiento de la Calidad de la Educación Media (MECE-MEDIA), centrado en el fortalecimiento de las capacidades de autonomía de los liceos para que pudieran construir una oferta educativa más eficiente, diversificada, de mejor calidad y más equitativa, a través de la descentralización pedagógica y propiciando un cambio integral de la cultura escolar que contempló la mejora de los recursos y las condiciones en que se desarrolla el trabajo escolar, para que sus procesos apuntaran a reforzar los resultados de la enseñanza y del aprendizaje de los estudiantes.

En este contexto, se requería contar con estrategias que generaran una mayor identidad y sentido de pertenencia de los jóvenes con su establecimiento, de manera que los propios estudiantes lograran convertir su liceo no sólo en un centro académico, sino también en un centro de referencia cultural, recreativo, social y afectivo. Esto debía procesarse a través de dos componentes fundamentales: fomento de la participación juvenil por un lado, y apertura efectiva del liceo a los intereses y expectativas de los estudiantes. En resumen, fortalecer la concepción de los jóvenes como co-constructores de la cultura escolar, a partir del reconocimiento de los saberes y quehaceres que identifican su entorno cultural, superando la concepción —más tradicional- de los estudiantes como re-productores de los saberes escolares institucionalizados y aportados desde quienes «saben» y «enseñan».

Para ello, desde el «Componente Jóvenes» se generaron las denominadas «Alternativas Curriculares de Libre Elección» (ACLES), diseñadas con el objetivo de ofrecer nuevas y atractivas oportunidades de uso del tiempo libre para y con los jóvenes, con la idea de complementar y enriquecer los demás aspectos de la vida escolar, tratar de 
que la cultura juvenil permeara el quehacer educativo, y convertir así los aprendizajes en algo entretenido y con significado real para sus destinatarios. Algunos eslóganes, como «aprender pasándolo bien» o «así también se aprende», reflejaban claramente el sentido de la propuesta.

Las evaluaciones realizadas cinco años después de iniciada la experiencia, demuestran que se desarrollaron 11 talleres con 200 participantes por liceo en promedio, totalizando 11 mil 600 talleres con 170 mil jóvenes en todo el país, alcanzando a más de la cuarta parte de la matrícula total. Tanto los estudiantes como los profesores han valorado muy positivamente la experiencia, destacando que la misma ha permitido mejorar las relaciones de los estudiantes entre sí, con los profesores y con otros jóvenes, todo lo cual se explica — según los actores implicados- por las metodologías (más flexibles y participativas) utilizadas. Sin embargo, se ha destacado que los estudiantes que participan son los más «integrados» a la cultura escolar, y que los liceos no se «apropian» efectivamente de la experiencia, lo que se explica - en los informes de evaluación- porque no se ha entrado realmente a fondo en el mundo de las culturas juveniles (especialmente en las vigentes en sectores populares) y porque se trata de procesos que requieren más tiempo para vencer resistencias enraizadas.

\section{b) Aprendiendo de otras experiencias (II): ¿Qué se está haciendo en la Argentina?}

Por su parte, en Argentina ha comenzado a operar una ambiciosa iniciativa en estas materias, denominada «Escuelas para Jóvenes» e impulsada desde el Ministerio de Educación, como una estrategia integral de reforma de la escuela media que responda con pertinencia a la heterogeneidad de situaciones específicas existentes a nivel nacional. El Programa prevé una inversión de 1200 millones de dólares, financiado en partes iguales con recursos del Presupuesto Nacional y un préstamo del Banco Interamericano de Desarrollo.

Con esta iniciativa, se pretende encarar varios problemas relevantes: baja calidad de los aprendizajes escolares, incapacidad para dar respuestas adecuadas al incremento y la diversificación de la demanda, ausencia de alternativas compensatorias para la retención de los alumnos en riesgo de fracaso escolar, distancia entre las propuestas vigentes en la normativa curricular y las prácticas de enseñanza efectivas en las aulas, persistencia estructural de un modelo institucional 
alejado de las necesidades actuales, régimen laboral y condiciones del trabajo docente poco apropiados para el desarrollo de propuestas de enseñanza potentes y relevantes, y falta de vinculación entre la cultura escolar y los intereses y expectativas de los jóvenes (según destacan los documentos oficiales).

La estrategia operativa del Programa está estructurada en torno a cinco ejes fundamentales: conformación de Equipos de Trabajo de Profesores, renovación de las prácticas de enseñanza y compensación de los aprendizajes, instalación de Centros de Actividades Juveniles, implementación de un proceso de evaluación permanente, y dotación de recursos y equipamiento y adecuaciones de infraestructura. Como puede apreciarse, se trata de componentes que de un modo $u$ otro están presentes en casi todos los procesos de reforma educativa en América Latina, y del conjunto, nos interesa concentrarnos en los Centros de Actividades Juveniles (CAJ) dado el sesgo con que está estructurado este trabajo.

Al respecto, el Programa se propone el siguiente objetivo: «ampliar el aporte formativo de la institución escolar a través de la instalación de Centros de Actividades Juveniles, para que los jóvenes puedan desarrollar, en la escuela o en instituciones de la comunidad con las que la escuela realice convenios, actividades culturales, deportivas, recreativas, de acción social comunitaria, etc., que trasciendan las previstas en el curriculum formal». Los resultados esperados se expresan así: «instalación en cada escuela de un Centro de Actividades Juveniles que brinde a los jóvenes oportunidades de desarrollo personal y social y respuesta efectiva a sus necesidades y aspiraciones culturales, interactivas, recreativas y educativas».

Entre las acciones previstas, se destacan: definición de lineamientos y criterios generales que enmarquen la organización de los CAJ, análisis de alternativas y de requerimientos para la instalación de los Centros, designación del personal necesario, formulación de la normativa que encuadre, posibilite y facilite las actividades, elaboración de una agenda de actividades anuales, definición y análisis de alternativas de organización de los alumnos, instrumentación de dispositivos de consulta y participación interna específicos, organización de espacios de participación para la comunidad y articulación de las pautas que se elaboren con los reglamentos de convivencia de las escuelas. 


\section{c) Aprendiendo de nuestra experiencia (I): la reforma de la educación media}

En nuestro medio, la reforma de la enseñanza media, expresada claramente en el Plan Piloto 1996 que se ha ido aplicando gradualmente hasta alcanzar a la casi totalidad de los establecimientos educativos medios, es un componente importante de la reforma educativa como conjunto, centrada a su vez en la universalización de la educación inicial y la búsqueda de una mayor equidad en la enseñanza primaria, a través del desarrollo de escuelas de tiempo completo en todo el país.

Los diagnósticos realizados en los últimos tiempos (especialmente desde la CEPAL) habían demostrado claramente que la enseñanza media se estaba desarrollando con grandes carencias, especialmente visibles en el escaso tiempo de permanencia de los estudiantes en el aula, la elevada rotación de los docentes entre diferentes establecimientos, la inexistencia de equipos de trabajo articulados en cada liceo, la falta de guías docentes y textos de estudio modernos y actualizados, y la insuficiente (y precaria en calidad) oferta de infraestructura física para responder a la creciente demanda de integración al sistema, por parte de un conjunto cada vez más heterogéneo de estudiantes.

Los documentos de la ANEP son muy claros en el destaque de los principales componentes de la reforma educativa a nivel medio, que para responder a las carencias destacadas, procuró centrarse en la extensión del horario de clase en el ciclo básico (de 3 horas y media a 5 horas y media diarias), el desarrollo de innovaciones curriculares (enseñanza por áreas de conocimiento, permanencia del docente en el establecimiento, estructuración de equipos docentes en cada liceo, etc.), la implementación de acciones instrumentales de apoyo (entrega de libros de texto a todos los estudiantes y guías docentes a todo el personal, puesta en marcha de centros de lenguas extranjeras, creación de inspecciones regionales en el ciclo básico, etc.), la creación de bachilleratos tecnológicos (ligados a sectores económicos de gran relevancia) y una gran inversión en infraestructura física (construcción y refacción de aulas en liceos y escuelas técnicas).

Así, y tal como se establece en la evaluación de la gestión 1995-1999 de la ANEP, «la educación media es el punto crítico de intersección de las propuestas de la Reforma ya que, por un lado, se consolida el proceso democratizador iniciado en la Educación Inicial asociado a una mejora de la equidad social y la calidad de los aprendi- 
zajes (educación obligatoria y universal), y por otro lado, se prepara el país para un mejor desempeño en un contexto globalizado, regionalizado y altamente competitivo (educación post-obligatoria con múltiples opciones)».

Sin duda, es mucho lo que resta por hacer, pero lo cierto es que el camino elegido es el correcto y los avances logrados distan de ser irrelevantes. Por ello, las actuales autoridades de la educación han emprendido nuevas iniciativas, tendientes a consolidar las reformas del ciclo básico y a la vez comenzar a encarar la reforma del segundo ciclo o bachillerato. Para ello, se está preparando la segunda fase del Programa MESyFOD (Mejoramiento de la Educación Secundaria y Formación Docente) que con el respaldo del BID, se pondría en práctica durante los próximos cuatro años, con una inversión total de 107 millones de dólares, dando continuidad — de este modo - al proceso comenzado en 1996.

\section{d) Aprendiendo de nuestra experiencia (II): el proyecto «punto de encuentro»}

En dicho marco, y a los efectos de nuestras preocupaciones específicas, se desarrolló en varios establecimientos el denominado «espacio adolescente», con reglas de juego más informales y flexibles, para fomentar acciones (elegidas en buena medida por los propios estudiantes) que permitieran el fomento de un mayor reconocimiento del liceo como un espacio propio de socialización juvenil, a los efectos de enfrentar los evidentes sentimientos de «ajenidad» de parte del estudiantado, pero en este sentido, los avances logrados han sido escasos, probablemente por la falta de persistencia y profundización en el camino elegido.

La ACJ colaboró en varios casos en el desarrollo de este tipo de experiencias (en el liceo $\mathrm{N}^{\circ} 8$ en 1996, en el liceo $\mathrm{N}^{\circ} 20$ entre 1998 y 2000), pero la experiencia más significativa se desarrolló en el liceo $\mathrm{N}^{\circ} 46$ en Paso de la Arena, a partir de un acuerdo de trabajo con el Programa MESyFOD, durante el segundo semestre del 2000. Los objetivos del programa, denominado «punto de encuentro» (acordados con la directora del liceo) fueron los siguientes: i) generar un espacio de encuentro para los adolescentes y jóvenes del liceo (recreativo, lúdico, formativo, de discusión y propuestas); ii) involucrar a los jóvenes en el cuidado e integración de su vida con la vida del local de estudio, con especial énfasis en la construcción de identidad y pertenencia al 
mismo; y iii) sensibilización, información y reconocimiento de sus derechos como adolescentes y jóvenes.

Para la obtención de dichos objetivos, se estructuró un equipo de trabajo (un coordinador, un animador y varios colaboradores), se definieron con los propios estudiantes las principales actividades a desarrollar (taller de candombe, taller de plástica, paseos, formación de animadores, etc.) y se desarrollaron las acciones de sensibilización y consulta tendientes a la integración de los estudiantes como tal. Es de destacar que la iniciativa no se limitó al trabajo con estudiantes, ya que involucró también a adolescentes de la zona, que en algunos casos habían pasado por el liceo pero habían abandonado sus estudios.

Los resultados obtenidos, indican que se involucraron alrededor de 80 de los 600 estudiantes del liceo (no estaba previsto trabajar con todos), y que el grado de satisfacción de los mismos fue sumamente elevado (a juzgar por sus propias evaluaciones). La iniciativa fue altamente valorada - también - por los docentes y por la directora (a través de las correspondientes evaluaciones) así como por parte de varios padres que se acercaron a señalar la pertinencia de la misma. Aunque resulta difícil «medir» efectivamente el impacto del proceso (no se contó con instrumentos específicos al respecto) existe acuerdo entre los participantes en que el espacio fue «apropiado» por los propios adolescentes, al tiempo que se logró mejorar el relacionamiento entre los mismos y entre éstos y el liceo, incluyendo en algunos casos cierta incidencia en el rendimiento escolar y la permanencia en el liceo (en el caso de potenciales «desertores», de no haber mediado la existencia del espacio como tal).

La experiencia, piloto por definición, podría y debería ser replicada en un número más amplio de establecimientos, desde el comienzo mismo del ciclo escolar, y de este modo se podría contar con elementos más amplios y sistemáticos para repensar el propio «espacio adolescente», como un componente que debiera contar con más «centralidad» en el contexto de la propia reforma educativa media en el futuro inmediato.

\section{4. ¿ ¿CÓMO MEJORAR LA GESTIÓN?: ALGUNAS PROPUESTAS ESPECÍFICAS}

El ejercicio retrospectivo y comparado que realizamos esquemáticamente en las páginas anteriores, sólo tiene sentido si sirve de base para «re-pensar» estos temas para su eventual reformulación 
futura. Y en ese sentido, esta sección y las siguientes, procuran realizar un ejercicio prospectivo y propositivo, que permita contar con insumos útiles al respecto.

\section{a) Construyendo liceos para jóvenes: repensar el espacio adolescente}

En primer lugar, se propone tomar debida conciencia de algo tan obvio como relevante: en la enseñanza media, estamos trabajando con adolescentes y jóvenes que ya no son niños y todavía no son adultos, que comienzan a recorrer el difícil camino de la emancipación respecto a sus referentes adultos (de sus padres en particular) y que pasan a valorar crecientemente otras «influencias socializadoras», en especial, a sus propios «pares» y a los medios masivos de comunicación, según ya hemos analizado en las secciones anteriores.

Desde este punto de vista, los liceos no pueden ser organizados con la misión exclusiva de preparar a los jóvenes para un buen desempeño en la vida adulta. Lejos de la lógica exclusivamente preuniversitaria del pasado, la enseñanza media debe tener sentido en sí misma, y no sólo en términos de ofrecer alternativas «terminales» relacionadas con la eventual inserción de los jóvenes en el mercado de trabajo (como alternativa al desarrollo de posteriores estudios terciarios) sino además - y fundamentalmente- como un espacio de socialización juvenil, que brinda apoyos efectivos a los jóvenes, en aquella difícil tarea de procesar adecuadamente su efectiva emancipación, construyendo sus propias identidades y ejercitando en la práctica la asunción autónoma de derechos y deberes, en términos de "proceso» a recorrer y asumido como tal por los jóvenes y sus referentes del entorno.

Para ello, el establecimiento educativo (liceo o escuela técnica) debería ser «apropiado» por los adolescentes y jóvenes, es decir, visto y asumido como un «espacio propio», en el que aquellos se sientan adecuadamente "contenidos» (apoyados efectivamente, pero con estricto respeto de su autonomía en proceso de construcción), y esto, a su vez, depende centralmente de que los jóvenes se sientan partícipes de la dinámica cotidiana de los establecimientos en los que permanecen durante una buena parte de su tiempo vital, en un contexto donde las «reglas de juego» sean claras y transparentes, especialmente en lo que atañe a la «toma de decisiones». Por lo dicho, este esquema se aleja claramente del modelo donde todo está regimentado y manejado por «otros» (la dirección, los adscriptos, los profesores, etc.), pero 
también del modelo que pretende crear mecanismos de «poder paralelo», visibles en las movilizaciones estudiantiles «en contra de la reforma educativa».

Una clave para estructurar este modelo participativo pero con reglas claras, podría estar dado por una reformulación profunda del espacio adolescente, que lo jerarquice y que le brinde una mayor centralidad en la dinámica del establecimiento educativo, en el que los propios estudiantes tengan una mayor y más efectiva participación en la toma de decisiones (qué hacer, cómo hacerlo, etc.) y en el que los «adultos» tengan un claro «perfil bajo», con funciones de acompañamiento «externas» desempeñadas por jóvenes mayores, que todavía sean percibidos como «pares» (animadores, recreadores, etc.) por los estudiantes.

\section{b) ¿Espacios paralelos o integrados?: actividades curriculares de libre elección}

Un aspecto central para concretar esta reformulación, a su vez, es el relacionado con el carácter de las actividades que se realicen en el espacio adolescente. Hasta el momento, lo que allí sucede es catalogado como «actividad extracurricular», lo cual, lleva a que los actores involucrados no le brinden la atención ni le otorguen la relevancia que dicho espacio tiene. Así, desde los docentes esto es percibido como una «carga adicional» o como un «recreo» informal, mientras que desde los estudiantes, el espacio pasa a ser percibido como algo irrelevante, estructurado con fines "paternalistas» por parte de los adultos (bien intencionados, pero adultos al fin) que pretenden ayudar «sin que nadie los haya llamado».

Una de las claves del éxito en este sentido, es que las actividades que se realicen sean «de libre elección» (los estudiantes quieren y deben aprender a tomar decisiones y a «negociar» con autonomía), pero para que sean asumidas con responsabilidad y con interés, deben ser estrictamente «curriculares», es decir, deben formar parte de las tareas que los actores relacionados con la dinámica educativa (estudiantes y docentes, en particular, pero no exclusivamente) tienen que cumplir como parte del "contrato» que se establece al momento de integrarse a dicha dinámica. Dicho de otro modo, para que este tipo de operativos tenga posibilidades de éxito, es vital que el espacio adolescente esté efectivamente integrado a la dinámica cotidiana, y que por tanto no sea percibido como un espacio paralelo, que no tiene mayor relevancia en lo que hace a la esencia de aquella dinámica. 
Esto debe ocurrir, además, a todos los niveles y todo el tiempo, dado que otro de los problemas que atenta contra el éxito de este tipo de iniciativas, se relaciona con la rigidez de los horarios, visible en particular en dos aspectos: la ubicación del «espacio adolescente» en los días sábado (ideal para «faltar», vaciando de contenido a la iniciativa) y el cierre del establecimiento educativo cuando no hay clases (noches y fines de semana, por ejemplo). Con todas las dificultades que implica en términos prácticos, resulta vital introducir cambios en ambas dimensiones, procurando que la lógica del espacio adolescente pueda permear al conjunto de la dinámica educativa y pueda facilitar el uso integral del espacio físico de los establecimientos, durante la mayor cantidad de tiempo posible.

Desde este punto de vista, los recreos pueden verse con otra óptica (el uso del cuerpo, por ejemplo, es percibido desde ópticas totalmente distintas entre adultos y jóvenes, y resulta vital comprender a fondo estas «lógicas») y del mismo modo, se pueden estructurar espacios físicos (algún salón de clase o espacios abiertos disponibles, por ejemplo) para facilitar dinámicas más informales, directamente administradas por los estudiantes (salas con juegos, refrescos y equipos de sonido, por ejemplo, o espacios para deportes, etc.).

Del mismo modo, los espacios administrados por los adultos (salas de profesores, oficina de la dirección, etc.) pueden «abrirse» más efectivamente, de modo que los estudiantes puedan percibirlos como espacios «amigables» (no necesariamente relacionados con el «control» y el «castigo») y hasta las propias prácticas pedagógicas pueden tornarse gradual, pero efectivamente cada vez más «participativas», relacionando los aprendizajes constantemente con la vida cotidiana de los adolescentes y procurando «integrar» los conocimientos a los efectos de facilitar la «comprensión del mundo» en el que vivimos.

\section{c) Todos cuentan: trabajando con estudiantes, padres, docentes y comunidad}

Para que este tipo de enfoques pueda funcionar fluidamente, resulta vital que todos los actores involucrados participen de las nuevas dinámicas a impulsar. Dicho de otro modo, el enfoque no se puede sostener sobre la base de un modelo donde un único actor (la autoridad educativa, por ejemplo) controla dicha dinámica y los demás (los padres, por ejemplo) son solo «convidados de piedra» que deben ayudar (en su casa) pero no molestar (en el establecimiento educativo). El 
ejemplo puede parecer extremo, pero lo cierto es que —en la práctica- esa «división del trabajo» tiene excesiva vigencia, y debe ser sustituida por otra más horizontal y participativa.

Llevado a sus extremos, el problema tiene que ver con concepciones muy arraigadas en nuestra sociedad, sustentadas en la idea de que los docentes enseñan y los estudiantes aprenden, en un contexto donde los padres deben «depositar» totalmente en el docente la función educativa de sus hijos. No es éste el lugar para discutir esta perspectiva, pero lo cierto es que se trata de un enfoque equivocado, y que produce consecuencias sumamente negativas en el proceso educativo, desde el momento en que se reduce la educación a uno solo de sus componentes (la enseñanza) dejando de lado el otro aspecto central (el aprendizaje). Desde este punto de vista, lo relevante es el aprendizaje, y en dicho marco, la enseñanza pasa a ser un aspecto puramente instrumental de la educación.

Sumado a ello, importa tener en cuenta que los aprendizajes son el resultado de muy diversas influencias «educativas», promovidas o protagonizadas por muy diversos actores, incluyendo de manera destacada (por todo lo ya dicho) a los grupos de pares, a los medios masivos de comunicación, a la familia y a los entornos comunitarios. Desde este punto de vista, entonces, resulta vital que la educación formal (la que se desarrolla en el establecimiento educativo formal) asuma sus funciones con mayor humildad y sin desconocer -todo lo contrario- la significativa influencia de los otros actores involucrados. Por ello, resulta vital que todos estos actores participen de la dinámica educativa formal, explícitamente y en base a reglas claras y acordadas colectivamente, pues de lo contrario, lo harán en base a reglas «opacas» y no consensuadas (y hasta impuestas en algunos casos).

Por ello, el espacio adolescente no puede ser visto como el espacio de los adolescentes (aislado de los otros espacios relevantes) manteniendo el espacio de la enseñanza como un espacio exclusivo de los docentes. Por el contrario, ambos espacios deben interrelacionarse dinámicamente entre sí, y articularse a la vez con los otros espacios relevantes, incluyendo de manera destacada a las familias y a los entornos comunitarios. Definitivamente, el aislamiento de la práctica educativa de los contextos reales en los que opera, sólo puede traer consecuencias negativas.

Para la enseñanza media, esto es vital. En el caso de los niños, la enseñanza primaria le organiza prácticamente todo en torno a la figura del maestro o maestra, mientras que en el caso del joven mayor 
de edad, la enseñanza superior deposita prácticamente todo en la propia capacidad organizativa del estudiante. ¿Y que ocurre en el medio? ¿Cómo vamos a manejarnos con los adolescentes? Definitivamente, resulta imperioso organizar este «tránsito», asumiendo cabalmente que estamos en una etapa de tránsito.

\section{d) Nuevas tecnologías de la información y la comunicación y práctica educativa}

Para completar el análisis que venimos realizando, resulta imperioso incorporar otra dimensión fundamental, relacionada con la dinámica de generación y transmisión de conocimientos, que como se sabe, se ha transformado radicalmente en las últimas décadas. Ya hemos incorporado en nuestros discursos estos cambios, pero todavía no hemos sido capaces de asumir sus consecuencias prácticas en nuestro trabajo cotidiano, al menos en las dimensiones en que ello es necesario.

Para empezar, importa recordar que a diferencia de lo que ocurrió al menos en la primera mitad del siglo XX, los saberes son hoy mucho más perecederos, en la medida en que la velocidad con que se genera el conocimiento ha crecido en forma exponencial. Allí están todas las teorías y enfoques que muestran que los principales activos de las naciones son hoy en día el capital humano y el capital social, al contrario de lo que ocurrió en el pasado, donde los principales activos se relacionaban con el capital productivo en sus diferentes variantes (agro, industria, servicios).

Pero además, también ha crecido exponencialmente la velocidad con que dichos conocimientos se transmiten, gracias a la evidente revolución procesada en los medios de comunicación y de transporte, empujada a su vez por los revolucionarios cambios producidos en las tecnologías de la información y la comunicación (fibra óptica, telefonía celular, redes satelitales, informática, internet, etc.). El Informe sobre el desarrollo humano 2001 del PNUD, por ejemplo, es más que elocuente (en evidencias empíricas y en enfoques interpretativos) en estas materias.

Sin embargo, apenas si empezamos a analizar las significativas consecuencias que todos estos procesos tienen y van a tener todavía más en el futuro, en relación a la dinámica educativa en particular y en relación a la socialización de las nuevas generaciones en un plano más general. Aunque ya se dispone de estudios sumamente rigurosos al respecto, el tema todavía se analiza en círculos muy restringidos de 
especialistas, sin que los actores que están viendo transformadas sus prácticas específicas (en el trabajo y en la vida cotidiana) puedan incorporarse dinámicamente al respecto.

Podemos ir más lejos todavía, y constatar que —en realidadtodavía seguimos mirando con desconfianza y hasta con hostilidad estos procesos, en parte porque nos cuesta comprenderlos cabalmente y en parte porque nos sentimos centralmente cuestionados en nuestras prácticas cotidianas (y ambas dimensiones son difíciles de aceptar). Incluso en los casos en que asumimos posturas más «modernas» y nos mostramos más «abiertos», caemos en respuestas exageradamente «simplistas», pretendiendo - por ejemplo- que todos los problemas se arreglen con la incorporación de la informática y el acceso a internet.

Lamentablemente, el tema es bastante más complejo, y nos obliga a caer en la cuenta de que la informática y la internet no son más que herramientas o instrumentos de trabajo, pero instrumentos y herramientas sumamente valiosos, si sabemos incorporarlos a nuestra labor con creatividad y con responsabilidad. El mismo enfoque vale para el caso de la televisión, donde también habrá que trabajar asumiendo la evidente complejidad del tema.

\section{ALGUNOS OBSTÁCULOS A REMOVER PARA AVANZAR CON EFICACIA}

¿Será posible encarar este tipo de enfoques, con ciertas probabilidades de éxito? Evidentemente, no será simple, pues se tendrán que enfrentar numerosas dificultades y problemas, que atentarán contra el proceso de cambio a impulsar. Veamos algunas de ellas.

\section{a) Los temores y las desconfianzas de los tomadores de decisiones}

Un primer conjunto de problemas, tendrá que ver centralmente con los temores y las desconfianzas de los tomadores de decisiones, no sólo a nivel macro, sino también a nivel micro, y no sólo en términos políticos, sino también en términos institucionales. Se trata, en todo caso, de actitudes «reactivas» que, aun desde antes de que ciertos procesos comiencen a operar, se despliegan con fuerza procurando neutralizar cualquier tipo de cambio o dudando fuertemente de la viabilidad de las propuestas que se intentan poner en práctica. 
Quienes ven con preocupación las movilizaciones estudiantiles y las ocupaciones de los establecimientos educativos que, año a año se despliegan en las mismas fechas y con idénticas orientaciones (aunque cada vez con menos fuerza), se resisten a promover cualquier propuesta que implique «participación» de los estudiantes. El enfoque tiene sólidos fundamentos (si se tienen en cuenta las prácticas que desarrollan sectores políticos radicales de izquierda, centradas en la politización de cualquier manifestación de rebeldía), pero confunde equivocadamente las relaciones causales entre fenómenos diferentes, y se priva de contar con la participación estudiantil en escenarios diferentes.

Por su parte, quienes miran estas propuestas desde la asignación de recursos, tienden a oponer resistencias casi automáticas a cualquier iniciativa que implique nuevos gastos. También este enfoque tiene sólidos fundamentos (si se tiene en cuenta que los recursos son siempre finitos y la lista de «asignaturas pendientes» en términos de prioridades a respaldar es muy larga), pero también confunde los términos del problema, en la medida en que no valora adecuadamente los «gastos» que se pueden evitar (por otras vías) con este tipo de inversiones. Si se pudiera demostrar (y ello sólo es posible a través de la práctica) que este tipo de propuestas puede disminuir la conflictividad, por ejemplo, las actitudes serían otras.

Un tercer grupo de actores (en todos los niveles) tiende a ver este tipo de propuestas como «amenazas» a las reglas de juego establecidas en general, y a los mecanismos de toma de decisiones en particular, y lo hacen desde posturas eminentemente defensivas, procurando resguardar sus propios espacios de poder (por muy limitados que éstos sean). En este caso, los argumentos son más «mezquinos» pero no por ello menos relevantes, y adicionalmente, también confunden peligros reales e imaginarios, sin tener debidamente en cuenta que - a veces - con la reformulación de ciertas reglas de juego, se puede ganar más de lo que se pierde (si es que se pierde efectivamente algo).

En todo caso, habrá que demostrar que aunque este tipo de resistencias cuentan con explicaciones sólidas, se basan en argumentos equivocados y sin fundamentos efectivos, de modo de trabajar en su neutralización, a los efectos de contar con este tipo de actores del lado del cambio y no del lado de la conservación de las reglas de juego establecidas. 


\section{b) Las inercias y las prácticas burocráticas del sistema educativo}

Todo otro conjunto de dificultades a enfrentar, se relaciona con las inercias y las prácticas burocráticas del sistema educativo como tal, que siempre es excesivamente lento y pesado para procesar cambios y tomar decisiones relevantes. Como se sabe, en cualquier institución compleja estas tendencias son casi «naturales» y hasta «inevitables», dado que casi siempre priman las actitudes defensivas ante cualquier tipo de ataque (sea real o percibido como tal aunque no lo sea realmente). Esto ha llevado a ciertos especialistas a sostener, por ejemplo, que resulta muy difícil que las instituciones complejas se sometan a sí mismas a procesos de cambio relevantes, de lo que derivan -incluso- enfoques relacionados con la necesidad de impulsos externos para procesar cambios desde afuera.

Definitivamente, para los propios operadores de cualquier institución compleja, es más fácil hacer las cosas como siempre, que tener que preocuparse por adaptar permanente y sistemáticamente cada actividad al entorno correspondiente y a las variables que juegan de manera diferente en cada caso concreto. Esto es válido, evidentemente, para un director que preferirá operar con las mismas rutinas de siempre (con el plantel docente, en la relación con los padres, en el vínculo con los propios estudiantes, etc.) que estar pendiente de la adaptación permanente (al menos, ante cada generación de estudiantes), pero también lo es para los propios docentes (de cualquier materia o asignatura) que preferirán reiterar una y otra vez la clase ya preparada con anterioridad, que someterse al desafiante trabajo de repensar en cada ocasión dicha clase.

Pero el tema afecta — también y sobre todo - al vínculo de los actores a un nivel más «agregado», especialmente en lo que atañe al relacionamiento entre cada establecimiento educativo y el nivel central del que dependen (por ejemplo), o entre los profesores que cumplen roles diferentes y teóricamente complementarios (como pueden ser la docencia, la inspección, el apoyo pedagógico, la supervisión administrativa, etc.) y aun entre funcionarios docentes y no docentes, que desempeñan funciones diferentes y establecen vínculos con la dirección del establecimiento en particular y con las autoridades del sistema como tal a nivel más general, también complejas y difíciles de reformular. 
En general, este tipo de instituciones complejas están rígidamente reguladas por leyes y decretos generales y específicos, que dejan poco margen a la innovación y a la creatividad, y el excesivo apego a las normas establecidas (fomentado por la lógica burocrática) inhibe muchas veces la promoción de cambios que pueden ser interpretados como ajenos a dichas normas y, por tanto, como hostiles a la dinámica acordada a través de los mecanismos correspondientes en lo previo. Alternativamente, los enfoques centrados en los resultados (más que en el cumplimiento de normas) aseguran teóricamente mejores impactos, pero los márgenes para controlar y evaluar el desempeño de los diferentes actores involucrados, son totalmente asincrónicos con la cultura dominante en estas materias.

Por lo dicho, habrá que trabajar también intensamente en la definición de estilos de trabajo que permitan ir incorporando innovaciones parciales o particulares, que puedan ir colaborando con la promoción de cambios relevantes, en términos de clima y de cultura institucional en estas y otras materias afines, para asegurar mayores posibilidades de éxito.

\section{c) Los prejuicios corporativos de la sociedad civil en relación al sistema educativo}

Un tercer grupo de dificultades a encarar, tiene que ver con el entorno del sistema educativo, y podría describirse haciendo referencia a los prejuicios existentes en la sociedad civil organizada y no organizada, en relación al mismo. En general, se trata de posturas críticas de agentes y actores relacionados de un modo u otro con la educación formal, que a menudo se estructuran en base a una excesiva simplificación de los problemas que se analizan, fenómeno que generalmente se deriva a su vez, de un desconocimiento significativo de las dinámicas efectivas con las que aquella funciona.

Aquí se mezclan lógicas muy diversas, relacionadas en algunos casos con intereses político partidarios en un plano general y/o con intereses corporativos más específicos (propios de la dinámica sindical de funcionarios docentes y no docentes, por ejemplo), pero en todos los casos, funcionan con una impronta particularista muy marcada, que prioriza los intereses específicos en detrimento de la dinámica del sistema educativo como tal, visto desde el cumplimiento de sus funciones esenciales. En algunos casos, incluso, estos enfoques impulsan iniciativas totalmente irracionales (si se las mira con cierta 
objetividad general) pero que son totalmente funcionales a los intereses específicos (la movilización de padres, por ejemplo, en la articulación de reclamos de diversa índole).

También en este caso, llevando el tema a sus extremos, podrían identificarse ciertas lógicas sumamente opinables, ligadas por ejemplo con el derecho que todos tenemos a participar de la definición de las grandes líneas orientadoras de la educación, que se expresa muchas veces en el impulso de enfoques que pretenden sustituir o condicionar las decisiones que toman las autoridades establecidas, confundiendo de este modo un derecho general con una potestad particular. El enfoque de ciertas agrupaciones estudiantiles, por ejemplo, que rechazan a las autoridades establecidas argumentando que ellos no las eligieron (desconociendo la lógica con que opera la democracia representativa) es muy elocuente al respecto, al igual que los enfoques de ciertas agrupaciones docentes que confunden instancias diferentes de participación (como lo son las Asambleas Técnico Docentes y el Sindicato, por ejemplo) que muchas veces se expresa en términos de confusión entre roles consultivos y decisorios, notoriamente diferentes y que no admiten superposición artificial (al igual que el tratamiento de temas diferentes en instancias diferentes, que no pueden mezclarse, como pueden ser condiciones laborales y criterios pedagógicos, por ejemplo).

En todos estos casos, estamos ante la vigencia de confusiones sumamente relevantes, que habrá que enfrentar decididamente, reivindicando el cumplimiento estricto de roles y funciones en cada caso particular, aun en los casos en que éstas y aquéllos deben ser desempeñados por las mismas personas (un docente, por ejemplo, que participa en una ATD y a la vez en el sindicato, o aun en alguna Comisión Especial estructurada con algún fin específico, al igual que un estudiante que puede participar - a la vez, pero de modos diferentes - en el espacio adolescente y en el movimiento estudiantil, por ejemplo). La clarificación de los roles y funciones que en cada caso se desempeñan, pasa a ser en este sentido, un factor decisivo para el éxito de la participación activa de los diferentes actores involucrados en estas dinámicas. No se trata, pues, de oponer participación y no participación, sino de clarificar rigurosamente qué tipo de participación vamos a impulsar. 


\section{d) Limitaciones y carencias de los medios masivos de comunicación}

Por último, en este inventario de obstáculos a superar, importa mencionar a los que se relacionan directa e indirectamente con las limitaciones y carencias de los medios masivos de comunicación en general (tanto privados como públicos) y de la televisión en particular. Dejar estas dimensiones por fuera del análisis que venimos realizando, implicaría quedarnos a mitad de camino, con respuestas parciales que no serán suficientes. Para empezar, habría que recordar que la influencia de estos medios en la socialización juvenil es tan evidente como preocupante, y analizar con cierta rigurosidad los fundamentos de tales preocupaciones.

Un primer argumento al respecto, tiene relación con la natural tendencia de los medios a vender excitación y fomentar el consumismo indiscriminado e ilimitado de todo tipo de bienes y servicios (reales o simbólicos) más allá de su valor efectivo. En efecto, existe un generalizado consenso en la censura a este tipo de prácticas mediáticas, que generan una gran contradicción entre el deseo de consumo y la posibilidad práctica de concretarlo, a todos los niveles por cierto, pero muy especialmente entre los sectores más empobrecidos, en los que este tipo de prácticas incita a obtener por vías irregulares lo que no puede obtenerse por los canales legítimamente establecidos desde el punto de vista social. Si bien los controles que puedan establecerse nunca son suficientes ni - en definitiva - efectivos, el tema debe ser encarado colectivamente, conciliando libertad de prensa e interés general.

En segundo lugar, importa analizar críticamente la imagen de los jóvenes que se ofrece — en general — a la sociedad en su conjunto, a través de los medios masivos de comunicación. Así, es mucha la evidencia acumulada que muestra claramente cómo los jóvenes que presentan los medios de comunicación son sólo un pálido reflejo de los realmente existentes, en la medida en que se prioriza la difusión de imágenes vinculadas con jóvenes de estratos medios y altos ligados al éxito, junto con otras relacionadas con jóvenes marginados ligados a prácticas delictivas, sin que los jóvenes realmente existentes (que no están ni en uno ni en otro grupo) aparezcan efectivamente, en términos de imagen dominante.

En tercer lugar, resulta imperioso encarar el tema de los mensajes que los medios emiten hacia los jóvenes como tal, esfera en la 
cual, las carencias son tan o más preocupantes, en la medida en que predominan los mensajes relacionados con el consumo, con el éxito individual (ligado al dinero o a la suerte), con la evasión pura y simple o con la promoción de comportamientos de riesgo en diversos planos operativos. En muchos casos, se argumenta que esto es así porque se responde a las demandas del público como tal, pero lo cierto es que no existen evidencias que lo demuestren, como tampoco existen evidencias que demuestren que no se pueden estructurar mensajes diferentes, sin perder audiencia.

Por último, será preciso encarar otro problema relevante, relacionado con el protagonismo de los propios jóvenes en el manejo de los medios de comunicación, tema vital desde el momento en que el principal instrumento para procesar con éxito la emancipación juvenil, es la participación efectiva a todos los niveles (y éste en particular, no debería ser una excepción al respecto), la que debiera procesarse sin confundir planos (como ya hemos destacado con anterioridad en un sentido más general).

\section{6. ¿ ¿POR DÓNDE EMPEZAR?: \\ ALGUNAS PROPUESTAS PARA LA ACCIÓN}

El proceso a desplegar es lo suficientemente amplio y complejo como para pretender operar en todas sus dimensiones desde un principio y simultáneamente, por lo cual, corresponde fijar algunas prioridades para comenzar a trabajar al respecto. Las cuatro dimensiones siguientes, podrían constituirse en un posible punto de partida.

\section{a) Culturas juveniles y formación docente: una integración necesaria}

En primer lugar, sería sumamente relevante operar sobre una de las variables claves, impulsando acciones específicas que permitieran dotar al cuerpo docente de herramientas modernas para la comprensión dinámica de las culturas juveniles dominantes en nuestro medio. En este sentido, resulta imperioso no limitarse a acciones de capacitación teórica, esfera en la cual, el sistema educativo cuenta con herramientas desde hace ya mucho tiempo (como la formación en psicología de la adolescencia, por ejemplo).

En realidad, se debería tratar de un ejercicio muy práctico, relacionado con la dinámica de grupos y prácticas juveniles muy concre- 
tas, actualmente en desarrollo, trabajando — por ejemplo— el tema de las culturas juveniles dominantes en diferentes estratos sociales, tomando debida conciencia de las especificidades actitudinales con las que operan los jóvenes provenientes de estratos populares (por ejemplo), notoriamente diferentes a las que predominan en los jóvenes pertenecientes a familias de estratos medios y altos.

Del mismo modo, se debería tratar de un ejercicio relacionado directamente con ofertas destinadas a los jóvenes y provenientes - por ejemplo- de los medios de comunicación, del estilo de los canales de televisión concebidos específicamente para jóvenes (como el popular MTV) o de series televisivas específicas (como el paradigmático caso de Gran Hermano, en estos momentos en particular) y aun de personajes de gran convocatoria entre los jóvenes (como es el caso de Petinati o Tinelli, según ya hemos comentado).

En la misma línea, se debería trabajar intensamente con los docentes en lo que atañe a los estilos musicales de mayor incidencia entre adolescentes y jóvenes, incluyendo el análisis de la imagen de los cantantes y estilos preferidos, así como los contenidos de sus canciones predilectas, sin descuidar el análisis de los estilos bailables asociados en cada caso, en el marco de la más precisa caracterización de los ambientes en que todos estos aspectos se desarrollan - $\tan$ exitosamente- entre nuestros estudiantes, procurando desentrañar sus claves de éxito y contrastándolas con las claves explicativas del rechazo o la indiferencia que generan - entre los mismos - las diversas prácticas institucionalizadas relacionadas con su formación personal y social (incluyendo la cultura dominante en liceos y escuelas técnicas).

No se trata - evidentemente - de contar con expertos en todas estas temáticas, pero lo cierto es que no se puede seguir operando sobre la base de la ignorancia de este tipo de dinámicas, o sobre la base de posturas meramente «reactivas» de parte de docentes que no alcanzan a comprender efectivamente las principales claves de las mismas o que las juzgan desde sus propios intereses y gustos (adultos) generando el inevitable rechazo entre los jóvenes y la consiguiente falta de empatía entre los dos protagonistas centrales del proceso educativo.

\section{b) Educadores y promotores: un diálogo para enriquecernos mutuamente}

En segundo lugar, sería altamente recomendable desplegar acciones y generar espacios para un fluido intercambio de experiencias 
entre educadores y promotores juveniles, asumiendo que se trata de dos tipos de prácticas diferentes pero complementarias, que operan en torno a un mismo tipo de destinatarios y que tienen mucho para aprender mutuamente al respecto, desde el momento en que ambas prácticas son educativas, diferenciadas por los mayores o menores niveles de formalidad e informalidad en el desarrollo de acciones específicas.

En este sentido, la articulación de prácticas de aprendizaje colectivas entre educadores formales e informales puede ser sumamente productiva para ambos, y para ello se podría trabajar fomentando una presencia más efectiva de ONGS en los establecimientos educativos (realizando tareas complementarias a las que protagonizan los docentes como tal), implementando talleres de reflexión colectiva en común en torno a la práctica educativa desplegada en uno y otro caso, sistematizando conjuntamente los aprendizajes metodológicos e institucionales correspondientes, y concertando roles y funciones diferentes pero complementarios, que permitan potenciar los impactos en los destinatarios de la labor efectiva de todos ellos.

Todo esto implicaría la superación de viejas y muy enraizadas prácticas vigentes en ambas esferas, sustentadas en prejuicios y estereotipos de diversa índole que no aportan nada demasiado relevante al respecto, al menos desde el punto de vista constructivo. Esto es particularmente notorio en lo que atañe a la pretensión existente en ambas esferas, relacionada con la propiedad exclusiva de saberes en estas materias, que no se sostiene desde ningún punto de vista, en la medida en que ambas tienen aportes sumamente valiosos y carencias sumamente relevantes, que no pueden desconocerse. Del mismo modo, esto es visible en los estériles debates acerca de las profesiones más pertinentes para el trabajo con adolescentes y jóvenes, terreno en el cual se pueden formular comentarios similares (¿cuál es más relevante?, ¿de cuál se podría prescindir?).

En todo caso, la clave es potenciar los aportes de todos los sectores involucrados, tratando de minimizar al mismo tiempo los efectos de las carencias o limitaciones respectivas, recordando siempre que todo saber específico es transitorio y circunstancial casi por definición, lo que obliga permanentemente a no tomar nada como definitivo o inmutable. En definitiva, lo que importa es la acumulación de saberes, y dicha acumulación sólo es viable si se asume que no existen monopolios en estas materias y que los resultados obtenidos dependen centralmente de la complementación de esfuerzos al respecto. 
Y para que este tipo de iniciativas sean exitosas, resulta fundamental que los debates se establezcan en torno a experiencias concretas y efectivas, poniendo al servicio de su análisis el instrumental teórico y metodológico con que se cuenta en cada caso, y evitando de este modo los debates estériles entre escuelas de pensamiento que poco o nada tienen para aportar en sí mismas, sin la imprescindible confrontación con la evidencia que brinda la propia experiencia de trabajo. Adicionalmente, se debería dotar a estos procesos de la necesaria continuidad en el tiempo, con la participación regular de los actores claves, procurando que las acciones que se impulsen no sean aisladas, desde ningún punto de vista.

\section{c) Animadores juveniles: un nuevo actor a incorporar dinámicamente}

En tercer lugar, sería altamente oportuno incorporar más y mejor a la dinámica de los establecimientos educativos, nuevos roles y funciones, complementarios de los ya existentes, a los efectos de potenciar los impactos efectivos en los procesos de aprendizaje. En particular, esto es relevante en lo que hace a la labor que han ido desempeñando en diversos contextos específicos los denominados «animadores juveniles», cumpliendo roles intermedios entre estudiantes y docentes (por ejemplo) y apoyando a ambos en sus procesos específicos.

En general, se trata de jóvenes que tienen algunos (pero no muchos) años más que los propios estudiantes, y que pueden ser percibidos por éstos como "pares» en la relación a establecer en la dinámica cotidiana de los establecimientos educativos medios como tal, sin confundirse plenamente con los estudiantes (elemento fundamental para lograr los objetivos que en general se fijan en este tipo de dinámicas grupales). Se trata, además, de jóvenes que han desarrollado capacidades específicas y acumulado cierta experiencia en el desarrollo de vínculos informales, pero efectivos (desde el punto de vista del proceso de maduración personal y social) con adolescentes y jóvenes menores a ellos, y que logran buenos niveles de empatía en la relación con aquéllos.

Las claves del éxito en estas materias, parece radicar en el hecho de que las distancias con la vida cotidiana y la cultura dominante entre los estudiantes existe, pero no es significativa, y ambos componentes del fenómeno son relevantes. El rol no puede ser desempeñado por un adolescente de la misma edad (porque pertenecería al 
grupo como uno más) y tampoco por un adulto (porque las distancias que lo separan de los adolescentes son muy significativas). La experiencia indica que, en el caso de los liceos privados (por ejemplo) este tipo de recursos humanos resultan claves para el manejo fluido de la dinámica cotidiana de los propios establecimientos, especialmente en lo que atañe al fomento de la participación de los estudiantes en muy diversas esferas.

Los animadores juveniles son - muchas veces - admirados por los estudiantes, y sirven como modelos de referencia en términos de construcción de identidades y en lo atinente a estilos de vida a imitar, con mayores o menores niveles de criticidad según los casos. Esto es particularmente relevante en lo que hace a la sexualidad adolescente, pero también lo es en lo que se refiere a relaciones sociales, valores compartidos, participación social y política, y muchas otras esferas vitales de los estudiantes. El desarrollo de relaciones de amistad entre animadores y estudiantes, permite el desarrollo de diálogos fluidos entre unos y otros, y hasta el establecimiento de espacios de complicidad que sólo excepcionalmente se logran entre docentes y estudiantes.

Por todo lo dicho, la incorporación de animadores juveniles a los equipos técnicos de los establecimientos educativos, puede potenciar significativamente el desarrollo de los procesos de aprendizaje y colaborar centralmente con la socialización juvenil, desde el desarrollo de prácticas de apoyo personal y grupal basadas en la confianza y en la equidad como regla de juego, diferente a la más desigual que establecen —en general- los docentes.

\section{d) Práctica educativa y comunicación masiva: otra integración posible}

Por último, en esta serie de propuestas más operativas, importa retomar el tema de los medios masivos de comunicación y de las nuevas tecnologías de la información, relacionándolas con la práctica educativa desde un enfoque alternativo al vigente, asumiendo que las lógicas predominantes en cada espacio en particular son muy diferentes.

La lógica de la educación formal, se basa en lo fundamental, en un proceso racional y deductivo, que nos lleva desde la construcción de grandes teorías explicativas a la realidad cotidiana, a través de largos y complejos procesos de abstracción, que no todos pueden seguir. En el fondo, esa es la lógica con la que fue construido el sistema educativo medio, cuando se destinaba a las élites conformadas por 
clases medias y altas (que eran las únicas que podía acceder a la educación) hace ya mucho tiempo. Pero la masificación y la diferenciación social de la matrícula, ha llevado a que los adolescentes y jóvenes pertenecientes a sectores empobrecidos (o directamente marginales) incorporados al sistema educativo, no puedan seguir dicho proceso, pues no disponen del tiempo ni de las condiciones familiares para efectivizarlo, lo cual explica en buena medida la crisis de la enseñanza media, medida en términos de fracaso escolar (por ejemplo).

En esencia, este proceso es notoriamente diferente al que rige a los medios masivos de comunicación, especialmente en el caso de la televisión, donde el lenguaje es más lúdico que conceptual, y mucho más afectivo y emocional que racional. Esto implica que no basta con elaborar mensajes para su transmisión televisiva (por ejemplo), pues si dichos mensajes se elaboran con la lógica del sistema educativo formal, el efecto va a ser totalmente nulo. Resulta decisivo lograr empatía emocional (primero) a través de la identificación de la audiencia con algún personaje clave (por ejemplo), para emitir mensajes (después) que sean recepcionados efectivamente. Una experiencia realmente importante desde este punto de vista, es la serie televisiva "Yizo Yizo», destinada a un público de 7 a 15 años que se ve bien retratado en sus episodios, ya que aborda la problemática de los alumnos de una escuela media popular en Sudáfrica. Concebida por el gobierno como un medio de conciliar a la juventud negra al borde de la marginalidad y la delincuencia con la escuela todavía asociada al poder blanco, y producida por creadores comprometidos con el tema, la serie cuenta con elevados niveles de audiencia y está logrando que el país empiece a dialogar consigo mismo, problematizando a todos los actores involucrados, en relación al tema.

Las nuevas tecnologías de la información y la comunicación, por su parte, pueden ampliar nuestro horizonte de posibilidades (en alcance, en calidad, en eficacia comunicativa, etc.), pero siempre que recordemos que son sólo instrumentos, que pueden ser utilizados a través de muy diversas estrategias pedagógicas y metodológicas. Desde este ángulo, por ejemplo, resulta vital incorporar la informática como una herramienta al servicio de toda la dinámica del establecimiento educativo, y no como una materia más y un espacio cerrado, creado con el fin de aprender destrezas específicas. Así, las computadoras y la internet (cuyo acceso será universal desde la enseñanza en algunos pocos años más) pueden ser herramientas fundamentales para el fortalecimiento y el desarrollo de espacio adolescente como tal, si 
se cambia el enfoque predominante hasta el momento, y lo mismo puede ocurrir con las actividades curriculares clásicas, en términos de apoyo informativo y documental, etc.

\section{7. ¿CÓMO ENCARAR ESTOS COMPLEJOS Y ATRACTIVOS DESAFÍOS?}

Finalmente, importa hacer algunas referencias adicionales en términos más estrictamente operativos, para concretar al máximo posible las propuestas que venimos formulando.

\section{a) Generalizar y profundizar la reforma educativa en la enseñanza media}

Para comenzar, importa contar con un contexto que favorezca la implementación de los cambios que estamos proponiendo, y para ello, resulta imperioso generalizar y profundizar el proceso de reforma educativa en el que estamos inmersos. Esto quiere decir, en primer lugar, que debe haber reglas de juego similares para todos los establecimientos educativos, en segundo lugar, que las opciones asumidas deben ser implementadas a todos los niveles, y en tercer lugar, que se deberá incentivar al máximo la dinámica reformista, procurando evitar las inercias burocráticas propias de cualquier proceso reformista.

La generalización de las mismas reglas de juego para todos los establecimientos educativos medios, es relativamente sencilla de concretar, aplicando en términos universales el Plan 1996, que ya se aplica en la gran mayoría de los liceos. Sin embargo, todavía quedan algunos establecimientos en los que este Plan no está vigente, y aunque esto no explica los problemas surgidos en el Liceo $\mathrm{N}^{\circ} 12$, lo cierto es que la implementación de este Plan en dicho establecimiento ayudaría a responder a los tristes sucesos allí ocurridos.

Así, resulta vital que la extensión horaria, la conformación de equipos docentes, la estructuración del currículo por áreas de conocimiento, la utilización efectiva de nuevas guías docentes y nuevos textos de estudio, y demás componentes de la reforma educativa en marcha, tengan plena vigencia en todos los establecimientos educativos, y que en todos ellos se desarrollen fluidamente todas las acciones relacionadas con el control y la evaluación de los aprendizajes efectivamente logrados por parte de los estudiantes, también diseñadas y estructuradas en el marco de esta reforma. 
En este contexto, la generalización de los Proyectos Educativos Liceales (PREL), de gran impacto en los casos en que dicha experiencia se puso en práctica, también podría colaborar centralmente en estas materias, en la medida en que dotaría a cada establecimiento de una hoja de ruta clara y precisa, adaptada claramente a las especificidades de cada realidad particular. Un mayor incentivo al respecto, incluyendo premios y castigos más específicos, podría ser clave a los efectos de que los actores centralmente implicados actuaran decididamente, aprovechando al máximo las posibilidades existentes en este marco.

El Perfil II del Programa de Modernización de la Educación Media y Formación Docente (MESyFOD) cuenta con orientaciones precisas en torno a estos temas, organizadas en cuatro componentes claves: «i) la consolidación del Ciclo Básico, incluyendo una nueva modalidad para atender a los jóvenes que desertaron del sistema, habiendo completado únicamente la primaria; ii) la transformación del Segundo Ciclo de la Enseñanza Media, tanto en las ofertas académicas como técnicas; iii) el fortalecimiento y consolidación del sistema de formación docente; y iv) el mejoramiento de los procesos y sistemas de información con miras a mejorar la eficiencia y gestión del sistema».

\section{b) Centros de participación juvenil: otro espacio para dinamizar la reforma}

En segundo lugar, sería fundamental consolidar espacios más claros y atractivos para fomentar la apropiación de los espacios educativos por parte de los estudiantes, profundizando el trabajo que se viene realizando en el denominado "espacio adolescente», y en este sentido, la creación de Centros de Participación Juvenil en los propios establecimientos educativos medios, podría ser en una respuesta pertinente y oportuna (hablamos de centros juveniles, porque los estudiantes se identifican como jóvenes y no como adolescentes, término que —además - tiene connotaciones muy opinables, es una construcción adulta, y genera rechazos entre los jóvenes cuando así se los califica).

Los CPJ podría cumplir varias funciones relevantes: servir de espacio para el nucleamiento informal de los estudiantes (que podrían desarrollar allí todo tipo de actividades culturales, recreativas y deportivas), facilitar el desarrollo de debates y reflexiones colectivas sobre todos aquellos temas que interesen en particular a los estudiantes (in- 
cluyendo la propia reforma educativa, la actualidad nacional e internacional, etc.), promover el involucramiento de los estudiantes en actividades más amplias de servicio a la comunidad (animación cultural, mantenimiento de espacios públicos, desarrollo de acciones solidarias, etc.) y cualquier otra iniciativa que los propios estudiantes prioricen al respecto.

Éstos deberían funcionar en base a reglamentos muy elementales, dirigidos por los propios estudiantes (a través de modalidades que ellos mismos definan), y contar con el pleno apoyo de las autoridades educativas a todos los niveles, incluyendo un apoyo sistemático y permanente de los animadores juveniles que — según ya hemos indicado - deberían integrarse protagónicamente a la dinámica cotidiana de los establecimientos educativos. Pero a la vez, deberían determinarse con precisión los límites correspondientes, procurando evitar la distorsión de estos espacios participativos, a partir de la injerencia de actores externos a la propia dinámica educativa, que no contaran con los avales de las autoridades establecidas.

Para ello, la esencia de los CPJ debería centrarse en el fomento de la participación juvenil a todos los niveles, pero sin que ello signifique pretender el involucramiento directo en la toma de decisiones respecto a los aspectos relacionados con la dinámica cotidiana de cada establecimiento, y menos aun, del conjunto de la reforma educativa. Una clara distinción entre consulta e involucramiento en la toma de decisiones, debe definir esto con total precisión, a través de mecanismos que de todos modos aseguren que la opinión de los estudiantes va a ser centralmente tenida en cuenta, al momento de tomar las correspondientes decisiones.

Pero lo más relevante para que estos espacios tengan los impactos que estamos buscando, es que los mismos sean efectivamente atractivos y respondan a necesidades sentidas de los adolescentes, y para ello, deberán estar adecuadamente equipados. Esto implica que se pueda tener acceso fluido a equipos informáticos conectados a internet, que se pueda disponer de implementos esenciales para el desarrollo de actividades lúdicas (equipos de sonido, utensilios deportivos, materiales didácticos, etc.) y que se pueda contar con apoyos externos adicionales, a los efectos de obtener otros implementos complementarios específicos (películas y videos, diarios y revistas, infraestructura para campamentos, etc.). 


\section{c) Debate abierto y comunicación masiva: otra apuesta posible y necesaria}

Una tercera dimensión en la que habría que operar decididamente en lo inmediato, es la relacionada con los medios masivos de comunicación, centrando las energías en el necesario debate a procesar sobre la pertinencia y la relevancia de los procesos de reforma que se vayan impulsando. En este sentido, parece evidente que existen varios temas neurálgicos en estas materias, que no podrán ser adecuadamente encarados, sin que medie el desarrollo de amplios y sólidos consensos sociales y políticos.

No corresponde hacer un inventario exhaustivo al respecto, pero importa recordar algunos de los más relevantes, destacando - entre otros- la vigencia cultural del modelo de educación secundaria puramente pre-universitario, el preocupante problema que representan las decenas de miles de jóvenes que ni estudian ni trabajan ni buscan trabajo, los elevados niveles de fracaso escolar (repitencia, extraedad, deserción, etc.) en términos de la eficiencia y la pertinencia de la educación que estamos ofreciendo, los escasos niveles de inversión de recursos en la enseñanza media, las precarias condiciones de trabajo de los docentes, y la insuficiente adecuación del currículo vigente a los desafíos de la compleja sociedad actual, tanto en términos económicos como en el terreno político, social y cultural.

La gravedad de estos fenómenos es tan evidente, que no es posible seguir discutiendo desde posiciones puramente corporativas o político partidarias, como se ha hecho hasta el momento. En realidad, se requieren debates más serios y sistemáticos, que apunten a la esencia de tales fenómenos en procura de explicaciones causales sólidas y bien fundamentadas, a efectos de poder contar con bases rigurosas para el diseño de respuestas alternativas, y para ello, resulta imperioso contar con instrumentos que permitan trascender los espacios utilizados hasta el momento para procesarlos.

Una posible vía al respecto, es contar con un conjunto de programas televisivos (que tengan enlaces con la dinámica radial y de la prensa escrita, por supuesto), que permitan que el tratamiento de estos temas se relacione creativamente con la dinámica cotidiana de las familias uruguayas (principales interesadas en que la educación funcione con los mejores estándares de calidad y logre los mejores resultados) y del conjunto de los actores directa e indirectamente relacionados con estas dinámicas, del estilo del ejemplo sudafricano antes 
mencionado (Francisco el Matemático, en Colombia, es otro ejemplo a tener en cuenta).

La forma en que efectivamente se plasme esta iniciativa, tendría que estar más cerca del teleteatro que del periodístico clásico, y tendría que estructurarse en torno a la difusión de imágenes y personajes con los que todos podamos identificarnos, más que en la emisión de mensajes de especialistas o tomadores de decisiones. Él o los programas no deberían preocuparse mucho por los resultados concretos (acuerdos específicos, por ejemplo), concentrándose más bien en la problematización del conjunto de la sociedad al respecto, de modo de contribuir significativamente con la jerarquización de estos temas en la agenda pública, a la que llegan sólo los temas promovidos por las diversas corporaciones sectoriales que cuentan con mecanismos eficientes para incidir en la toma de decisiones. La televisión estatal, podría tener un claro protagonismo en estas materias, si pudiera concretar el proceso de modernización en el que están empeñadas las actuales autoridades.

\section{d) La contribución de la ACJ: experiencia, valores y compromiso institucional}

En todas estas dimensiones, la ACJ podría contribuir decididamente, a los efectos de sumar sus energías y saberes, involucrándose centralmente en el propio proceso de reformas, a partir de sus propias definiciones institucionales, y en una gran sintonía con los enfoques dominantes en estas materias. Para ello, sería elemental profundizar los acuerdos con los que se viene trabajando hasta el momento, asumiendo colectivamente el despliegue de esfuerzos conjuntos basados en actitudes proactivas, propias de instituciones públicas y privadas que se asocian con autonomía y con decisión al respecto, procurando el logro de objetivos comunes en beneficio de los destinatarios directos e indirectos de los mismos.

Ello puede ser así, porque estamos ante una organización con más de noventa años de presencia activa en la sociedad uruguaya, y que cuenta con recursos humanos, infraestructurales y financieros propios, que permiten fundamentar su existencia sin depender de apoyos estatales o de empresas privadas, todo lo cual puede facilitar el establecimiento de acuerdos de trabajo que no se rijan por simples relaciones contractuales y que pueden asegurar el desarrollo de procesos sostenidos en el tiempo (evitando las acciones puramente puntuales, que se agotan en sí mismas y tienen límites muy evidentes). 
En este sentido, la ACJ puede aportar su larga y fecunda experiencia en el trabajo con niños, adolescentes y jóvenes (de todos los estratos sociales, en todo el país), tanto en lo que hace a sus propias iniciativas (con sus propios socios) como en lo que atañe a los acuerdos impulsados con una amplia gama de instituciones públicas y privadas a lo largo de toda su historia institucional (con el Instituto Nacional del Menor, con el Instituto de la Juventud, con la propia ANEP en relación a las Escuelas de Tiempo Completo, con varias Secretarías de Estado, con Intendencias Municipales, con empresas públicas y privadas, con ONGS, etc.), cumpliendo en este sentido con relevantes funciones ligadas al tendido de puentes entre actores muy diversos, a partir de un conjunto básico de valores compartidos sumamente relevantes, centrados en un compromiso indeclinable con el desarrollo humano desde un enfoque integral.

En particular, la ACJ podría colaborar centralmente con la selección y formación de animadores juveniles (apoyando sistemáticamente su labor cotidiana a posteriori), con la integración dinámica de voluntarios dispuestos a colaborar en cualquiera de las dimensiones anteriormente destacadas, con la dinamización de los Centros de Participación Juvenil como tal, con el desarrollo de acciones de capacitación docente en estas materias, con el tendido de puentes entre todos los actores involucrados, con el impulso de acciones relacionadas con la comunicación masiva, con la organización y desarrollo de foros de debate e intercambio de experiencias, con el monitoreo y la evaluación participativa de todos estos procesos, y con todas aquellas otras dimensiones en las que se considere útil y pertinente el aporte institucional en estos dominios.

Un acuerdo de trabajo general entre las autoridades de la enseñanza media y la ACJ, podría sentar las bases necesarias para impulsar estos esfuerzos comunes, al tiempo que otro más preciso y efectivo con los Programas de Modernización de la Enseñanza Media (MESyFOD y UTU-BID) podría permitir la operativización concreta al respecto, en las áreas y acciones que se prioricen de común acuerdo entre las partes. 


\section{REFERENCIAS BIBLIOGRÁFICAS}

ACJ (2000): «Proyecto Punto de Encuentro del Liceo $N^{\circ} 46$ de Paso de la Arena. Informe final de la experiencia piloto». Montevideo: ACJ y Programas MESyFOD y UTU/BID.

ANEP (2001a): «Estudio sobre la predisposición al abandono escolar en estudiantes del tercer año de enseñanza media a partir de los datos del censo de aprendizajes 1999». Montevideo: Programas MESyFOD y UTU/BID.

_ (2001b): «Análisis del perfil de las familias de los estudiantes de los terceros años del ciclo básico de educación media a partir de los datos del censo de aprendizajes 1999». Montevideo: Programas MESyFOD y UTU/BID.

- (2000a): Una visión integral del proceso de reforma educativa en Uruguay 1995-1999. Montevideo: ANEP.

(2000b): «Propuestas de mejoramiento de centros de educación media». Montevideo: CODICEN-ANEP, Programas MESyFOD y UTU/BID.

ARIAS, EDGAR (1998): Pasajeros del silencio: juventud, cultura y voluntad de saber. Medellín: Instituto Juventud XXI.

BANCO MUNDIAL (1999): El conocimiento al servicio del desarrollo. Informe sobre el desarrollo mundial 1998/1999. Washington: Banco Mundial.

BARBERO, JESÚS MARTíN y otros (2000): Umbrales: cambios culturales, desafíos nacionales y juventud. Medellín: Corporación Región..

Bressser Pereira, C. y N. Cunill Grau (editores) (1998): Lo público no estatal en la reforma del Estado. Buenos Aires: Editorial Paidós.

BRUNNER, JOSÉ JOAQUín (2000): «Educación: escenarios de futuro. Nuevas tecnologías y sociedad de la información». Documento de Trabajo $\mathrm{N}^{\circ} 16$. Santiago: PREAL.

Burbules, N. y T. CALLISTER (2001): Educación: riesgos y promesas de las nuevas tecnologías de la información. Madrid: Editorial Granica.

CAfiero, M.; M. MARAFioti y N. TAgliabue (editores) (1997): Atracción mediática: el fin de siglo en la educación y la cultura. Buenos Aires: Editorial Biblios.

CASTELlS, MANUEL (1997): La era de la información: economía, sociedad y cultura. Madrid: Alianza Editorial (tres tomos). 
CASTILLO, JORGE (2000): «Alternativas curriculares de libre elección: una mirada evaluativa (1994-1999)». Documento de Reflexión del Componente Jóvenes. Santiago: Programa MECEMEDIA, Ministerio de Educación.

CePAl (2000a): Panorama social de América Latina 2000. Santiago: CEPAL.

(2000b): Equidad, ciudadanía y desarrollo. Santiago: CEPAL.

y CELADE (2001): Juventud, población y desarrollo en América Latina y el Caribe: problemas, oportunidades y desafíos. Libros de la CEPAL $\mathrm{N}^{\circ} 59$. Santiago: CEPAL.

— y - (2000): «Adolescencia y juventud en América Latina y el Caribe: problemas, oportunidades y desafíos en el comienzo de un nuevo siglo». Presentado en la X Cumbre Iberoamericana de Jefes de Estado y de Gobierno (Panamá). Santiago: CEPAL.

COSTA, P.; J. PÉREZ y F. TROPEA (1996): Tribus urbanas: el ansia de identidad juvenil: entre el culto a la imagen y la autoafirmación a través de la violencia. Barcelona: Editorial Paidós.

DEDE, CHRIS (compilador) (2000): Aprendiendo con tecnología. Buenos Aires: Editorial Paidós.

ESPINOZA, VICENTE y otros (2000): «Ciudadanía y juventud: análisis de los perfiles de oferta y demanda de las políticas sociales ante la nueva realidad juvenil». Santiago: Instituto de Estudios Avanzados, Universidad de Santiago de Chile.

FEIXA, CARLES (1998): El reloj de arena: culturas juveniles en México. México: CIEJUV y Causa Joven.

FILGUEIRA, CARLOS (1998): Emancipación juvenil: trayectorias y destinos. Montevideo: CEPAL. (Con la colaboración de Álvaro Fuentes).

FUENZALIDA, VALERIO (2000): La televisión pública en América Latina: reforma o privatización. Santiago: FCE.

GANDARA, SANTIAGO y otros (1997): Vidas imaginarias: los jóvenes en la tele. Buenos Aires: Editorial Biblios.

KAZTMAN, RUBÉN (coordinador) (1999a): Desarrollo humano en Uruguay, 1999. Montevideo: PNUD.

- (coordinador) (1999b) Activos y estructuras de oportunidades: estudios sobre las raíces de la vulnerabilidad social en Uruguay. Montevideo: CEPAL-PNUD.

; F. Filgueira y M. Furtado (2000): «Nuevos desafíos para la equidad en el Uruguay». Revista de la CEPAL N${ }^{\circ} 2$. Santiago: CEPAL. 
KLIKSBERG, B. y L. TOMASSINI (compiladores) (2000): Capital social y cultura: claves estratégicas para el desarrollo. Washington: BID-FCE.

LEVIS, DIEGo (1997): Los video juegos: un fenómeno de masas. Que impacto produce sobre la infancia y la juventud, la industria más próspera del sistema audiovisual. Buenos Aires: Editorial Paidós.

MARAFIOTI, ROBERTO (editor) (1997): Culturas nómades: juventud, culturas masivas y educación. Buenos Aires: Editorial Biblios.

MARGULIS, MARIO (editor) (1996): La juventud es más que una palabra: ensayos sobre cultura y juventud. Buenos Aires: Editorial Biblios.

MinisTERIO DE EDUCACION (2001): Escuelas para jóvenes. Buenos Aires: Ministerio de Educación.

Moura CASTRO, ClAUdio (editor) (1999): La educación en la era de la informática: qué da resultado y qué no. Washington: BID.

NAVARRO, J. C.; K. TAYLOR; A. BERNASCONI y L TYLER (editores) (2000): Perspectivas sobre reforma educativa: América Central en el contexto de políticas de educación en las Américas. Washington: USAID-BID-HIID.

O’Donnell, JAMES (2000): Avatares de la palabra: del papiro al ciberespacio. Buenos Aires: Editorial Paidós.

OIT (2001): La vida en el trabajo en la economía de la información. Informe sobre el empleo en el mundo 2001. Ginebra: OIT.

OPERTTI, RENATO (2000): «El proceso de reforma educativa en Uruguay: gestión pública y resultados obtenidos entre 1995 y 1999». En VARIOS AUTORES: «¿Hacia donde va el gasto en educación? Logros y resultados». Volumen II: Reformas Sectoriales y Grupos de Interés. Serie Políticas Sociales N², Santiago: CEPAL.

OYARZÚN, A.; R. IRRAZABAL; I. GOICOVIC y L. REYES (2001): Entre jóvenes re-productores y jóvenes co-constructores: sentidos de la integración en la cultura escolar. Viña del Mar: Ediciones CIDPA.

PÉREZ TORNERO, JOSÉ MANUEL (compilador) (2000): Comunicación y educación en la sociedad de la información: nuevos lenguajes y conciencia crítica. Buenos Aires: Editorial Paidós.

PIECK, ENRIQUE (coordinador) (2001): Los jóvenes y el trabajo: la educación frente a la exclusión social. México: Universidad Iberoamericana, IMJ, UNICEF, CINTERFOR. 
PisCitelli, AleJANDRO (2001): La generación Nasdaq: apogeo (¿y derrumbe?) de la economía digital. Buenos Aires: Editorial Granica.

(1998): Post televisión: ecología de los medios en la era de internet. Buenos Aires: Editorial Paidós.

(1995): Ciberculturas en la era de las máquinas inteligentes. Buenos Aires: Editorial Paidós.

PNUD (2001): Poner el adelanto tecnológico al servicio del desarrollo humano. Informe sobre desarrollo humano 2001. Madrid: Mundiprensa.

- (1998): Educación: la agenda del siglo XXI. Hacia un desarrollo humano. Bogotá: Tercer Mundo Editores.

RIFKIN, JEREMY (2000): La era del acceso: la revolución de la nueva economía. Buenos Aires: Editorial Paidós.

RIVERO, José (2000): Educación y exclusión en América Latina: reformas en tiempos de globalización. Lima: TAREA.

RODRÍGUEZ, ERNESTO (2001): Jóvenes en América Latina: actores estratégicos del desarrollo. México: Centro de Investigaciones y Estudios sobre Juventud (CIEJUV), Instituto Mexicano de la Juventud (IMJ).

RoJAs, Claudio (editor) (2000): Desafíos de la sociedad de la información en América Latina y Europa. Primer foro de las comunicaciones. Santiago: Editorial LOM-UNICOM.

SARTORI, GIOVANNI (1998): Homo videns: la sociedad teledirigida. Madrid: Editorial Taurus.

TENTI, EMILIO (compilador) (1999): Una escuela para los adolescentes: reflexiones y valoraciones. Buenos Aires: Editorial Losada - UNICEF.

Urteaga, MARITZA (1998): Por los territorios del rock: identidades juveniles y rock mexicano. México: CIEJUV - Causa Joven.

UNESCO-CEAAL-CREFAL-INEA (2000): La educación de personas jóvenes y adultas en América Latina y el Caribe: prioridades para el siglo XXI. Santiago: UNESCO.

VAlenZuela, José MANUEl (1997): Vida de barro duro: cultura popular juvenil y graffiti. Tijuana: Universidad de Guadalajara, Colegio de la Frontera Norte.

VARIOS AUTORES (2000): «Tecnologías de la información y la comunicación en la educación». Revista Iberoamericana de Educación N²4. Madrid: OEI. 
(1999): Jóvenes, cultura juvenil y subjetividad en el Chile de los noventa. Estudios del INJUV $N^{\circ} 1$. Santiago: Instituto Nacional de la Juventud.

(1998): Viviendo a toda: jóvenes, territorios culturales y nuevas sensibilidades. Bogotá: Universidad Central, Siglo del Hombre Editores. 